\title{
La responsabilidad del Estado frente al Sistema Interamericano ${ }^{1}$
}

Estudiantes de la Facultad de Derecho.

\section{Socorro Alvarez Meneses Mario Germán Sánchez González}

4

12 de marzo de 1995, el indígena Clemencio Choachí González fue capturado en la ciudad capital de un Estado Suramericano, debido al señalamiento que María Pérez le hiciera como responsable de haberla accedido carnalmente el día anterior. Luego de permanecer cinco días en poder de los agentes de policía, Choachí fue entregado a disposición del funcionario judicial competente, iniciándose así una investigación penal en su contra.

El 13 de marzo del mismo año, asistido por un ciudadano honorable, Choachí rindió indagatoria, en la cual informó que era miembro de una comunidad indígena ubicada al interior del Estado, donde nació el 1 de enero de 1977 y que llevaba un mes en la ciudad capital, porque quería conocerla y tener otra visión del mundo; señaló que antes y después de ser llevado a Medicina Legal los agentes de policía lo habían torturado y que fue obligado por los mismos agentes a declarar que hacía parte de un movimiento paramilitar denominado "MDED", el cual había sido creado en diciembre de 1995.

El mencionado ciudadano honorable, asignado al Clemencio Choachí, le asistió judicialmente en casi toda la etapa instructiva, hasta el 10 de mayo de 1995, cuando éste otorgó poder a un abogado de confianza, quien nunca se hizo presente en las subsiguientes actuaciones judiciales.

Una vez resuelta la situación jurídica, le fue impuesta medida de aseguramiento consistente en detención preventiva sin beneficio de excarcelación, siendo recluido en la penitenciaría central de la cuidad, lugar destinado para atender a los condenados y en el cual existían otras personas menores de edad en compañía de adultos, siendo algunas de ellas indígenas.

El 17 de julio de 1995 ante la ausencia de su abogado de confianza, se solicitó a la dirección de Defensoría Pública la designación de un Defensor Público,

\footnotetext{
${ }^{1}$ Este es un caso ficticio. Los hechos corresponden al asunto planteado a resolver por los participantes del Segundo Concurso Universitario de Derechos Humanos, realizado en el mes de octubre de 2003 en la Ciudad de Popayán (Cauca).
} 
abogado que solicitó la nulidad del proceso por violación del derecho de defensa al no haber sido asistido por un defensor en las diligencias de práctica de pruebas, así como también por no presentar alegatos precalificatorios. Dicha solicitud de nulidad fue negada pơr la autoridad judicial en lo correspondiente con los alegatos preçalificatorios, pero se aceptó respecto a la etapa probatoria, ordenándose la repetición de las pruebas.

Culminada la audiencia pública y luego de establecer la existencia del delito y la responsabilidad del procesado, un juez de la República profirió, el 15 de febrero de 1996 , sentencia condenatoria por el delito de acceso carnal. Sentencia que fue apelada ante el Honorable Tribunal, instancia que el 20 de febrero de 1997 confirmó la decisión del a quo. Posteriormente, en el desarrollo del Recurso Extraordinario de Casación, el 15 de julio de 2001 , la Corte desestimó los cargos en su integridad pero ordenó la libertad del condenado por pena cumplida.

El 1 de octubre de 2001 Choachí González instauró Acción de Tutela contra las sentencias condenatorias detalladas, alegando que las mismas constituían vías de hecho, por cuanto no se le valoró la calidad de indígena y de menor de edad y en consecuencia no podía haberse iniciado y adelantado en su contra el proceso penal al que fue sometido; sin embargo, el citado amparo constitucional le fue negado por el Tribunal Seccional el $10 \mathrm{de}$ octubre de 2001 , decisión que más tarde fue confirmada por la Corte el 1 de diciembre de 2001, con fundamento en que la Acción de Tutela no es el mecanismo idóneo para atacar o impugnar providencias judiciales que han alcanzado la ejecutoria material.

El caso del indígena Clemencio, se repite frecuentemente en los diferentes Estados democráticos, donde las instituciones legitimamente constituidas muchas veces son las primeras violadoras de los Derechos humanos por sus conductas activas u omisivas, en contra de las garantías fundamentales reconocidas internaciorralmente a los habitantes de un país. Muchas historias concluyen así, cuando aparentemente se han agotado todas las instancias posibles para la protección de sus derechos, con un Estado que olvida la limitación y legitimidad que imponen a su actuar los Derechos Humanos de que son titulares las personas sujetas a su jurisdicción y finalmente, con un condenado que lejos de sentir compensado el daño causado, se siente vilipendiado, burlado y desconocida su dignidad humana al no haber recibido un debido proceso legal.

Podría pensarse que quien fue objeto de un proceso jurisdiccional sin la observancia de las garantías judiciales, está en la obligación de soportar cargas que ilegítimamente impone el Estado, originadas en la no observancia de normas de procedimiento, sean legales y/o constitucionales, así como de los compromisos internacionales que han sido adquiridos.

Sin embargo y debido a la común ocurrencia de la anterior situación y 
con el animo de prever los perjuicios que se pueden ocasionar a las personas por parte de un Estado en las diferentes esferas de su actuar, las naciones del mundo, comprometidos en la protección del individuo e inspirados en el principios Pro Homine, suscribieron la Declaración Universal de Derechos Humanos ${ }^{2}$, llegando àí a un consenso sobre la forma como los Estados deberían, en palabras de Rousseau, tratar a sus asociados.

Para que el deseo materializado en la Declaración Universal no se quedara en una simple retórica humanista y para lograr efectivizar este catalogo de buenas intenciones se crearon posteriormente por parte del Sistema Universal de Protección de los Derechos Humanos, encarnado en la ONU, dos grandes Pactos Internacionales ${ }^{3}$ y una serie de convenios y pactos sobre violaciones específicas de derechos y libertades, que imponen obligaciones escritas a los Estados que-los han suscrito, ratificado y que van mas allá de las directrices morales enunciadas en la Declaración.

La ONU, como materialización del Sistema Universal de Protección de Derechos Humanos, está compuesta por diversas instancias para el logro de sus cometidos principalmente por la Asamblea General, el Consejo Económico y Social, la Comisión y el Comité de Derechos Humanos, la Secretaría General, el Tribunal Internacional de Justicia y demás órganos asociados; estructura que se asimila a la de los diferentes Sistemas Regionales ${ }^{4}$ creados para posibilitar la resolución de los conflictos suscitados en relación con los derechos humanos de una forma más eficaz y habitual.

La Convención Americana sobre Derechos Humanos creada en $1969^{5}$, se convirtió en el primer instrumento jurídico de la región con carácter vinculante que codificaba los Derechos Humanos y creó un Sistema Institucional compuesto por la Comisión y la Corte Interamericana, para la defensa de los derechos contemplados en ella ${ }^{6}$.

En este orden de ideas, el Sistema Interamericano de Protección de los Derechos Humanos ha sido establecido como un régimen de libertad personal y de justicia social, fundado en el, "respeto de los derechos esenciales del hombre, derechos que no nacen del hecho de ser nacional de determinado Estado, sino que tienen como fundamento los atributos de la persona humana, razón por la cual justifica una protección internacional, de naturaleza convencional, coadyuvante o complementaria de la que ofrece el

\footnotetext{
${ }^{2}$ Proclamada en Paris, por la Asamblea General de la Organización de las Naciones Unidas el 10 de diciembre de 1948.

${ }^{3}$ Pacto Internacional de Derechos Civiles y Políticos y Pacto Internacional de Derechos Económicos, Sociales y Culturales, suscritos en 1966 y entrados en vigor once años después.

${ }^{4}$ Sistema Europeo, Sistema Africano y Sistema Americano de Protección de Derechos Humanos.

${ }^{5}$ Adoptada en la Conferencia Especializada Interamericana.

${ }^{6}$ GONZÁLEZ, Volio Lorena. Instituto Interamericano de Derechos Humanos. Pág. 38.

7 Tomado del preámbulo de la Convención Americana sobre Derechos Humanos o Pacto de San José de Costa Rica de 1969.
} 
derecho interno de los Estados Americanos ${ }^{7}$, desafiando en cierto modo el principio de Soberanía Absoluta de los Estados Nacionales, como una manifestación más del fenómeno globalizante.

La Corte Interamericana de Derechos Hunranos es una institución judicial autónoma, que goza de autoridad para decidir cualquier caso relativo a la interpretación y aplicación de la convención y para disponer que se garantice a la victima de la violación de un derecho o libertad protegidos por esta, el goce del derecho o libertad conculcados $^{8}$, pues sus decisiones surten efectos vinculantes para los Estados en litigio.

Por su parte, la Comisión Interamericana de Derechos Humanos está facultada para tramitar quejas o denuncias presentadas por cualquier persona, grupo $o$ entidad no gubernamental legalmente reconocida en uno o más Estados miembros de la OEA, siempre que se hayan agotado los recursos de jurisdicción interna, que sea presentada dentro del plazo de 6 meses a partir de la fecha en que el presunto lesionado en sus derechos haya sido notificado de la decisión definitiva, que la materia de la petición no este pendiente de otro procedimiento de arreglo internacional y que este plenamente identificado el petente.

Sin embargo, en algunos casos se presentan excepciones a los anteriores requisitos, como cuando no existe en la legislación interna del Estado de que se trata el debido proceso legal para la protección del derecho o derechos que se alega han sido violados o no se le ha permitido al presunto lesionado en sus derechos el acceso a los recursos de la jurisdicción interna, entre otras situaciones $^{9}$.

Es así como en el presente caso, Clemencio Choachí González, en nombre propio y asesorado por la "Organización Indígena y de las Minorías Étnicas", ONG con sede en varias capitales de América, presentó queja ante la Comisión Interamericana de Derechos Humanos el 15 de febrero de 2002. Se dijo por el quejoso que el Estado le había vulnerado los derechos y garantías consagradas en los artículos $3^{\circ}, 5^{\circ}, 7^{\circ}, 8^{\circ}, 19^{\circ}, 25^{\circ}$ y $26^{\circ}$ de $1 \mathrm{a}$ Convención Americana de Derechos Humanos, todo en relación con el artículo $1^{\circ}, 1$ ibídem. Igualmente, que se habían violado los derechos detallados en los artículos $3^{\circ}$ y $16^{\circ}$ del Protocolo Adicional a la Convención Americana sobre Derechos Económicos Sociales y Culturales, más conocido como Pacto de San Salvador. Igualmente, fueron desconocidos los derechos establecidos por la Convención de los Derechos del Niño en sus artículos $30^{\circ}, 37^{\circ}$ y $40^{\circ}$ y por la Convención Interamericana para prevenir y sancionar la tortura en sus artículos $1^{\circ}, 2^{\circ}$ y $9^{\circ}$.

En atención a la queja, la Comisión inició el trámite correspondiente,

${ }^{8}$ Opinión Consultiva 10 de 1989. Interpretación de la Declaración Americana de los Derechos y Deberes del Hombre en el marco del artículo 64 de la Convención Americana sobre Derechos Humanos.

${ }^{9}$ Artículo 44 a $46 \mathrm{CADH}$. 
presentando la situación expuesta a disposición de las partes para una solución amistosa, la cual resultó fallida.

Continuando con el procedimiento, el 20 de febrero de 2003, la Comisión presentó un iniforme confidencial al Estado sobre el fondo del asunto donde le hace algunas proposiciones y recomendaciones ${ }^{10}$, alertándole que no puede publicarlo. Le indicó que era internacionalmente responsable por las violaciones presuntas de los derechos del indígena Clemencio Choachí González.

El Estado manifestó que estaba haciendo lo necesario, teniendo presente las dificultades propias por las que atravesaba, ocasionadas por el conflicto armado que vivía el país, para que las recomendaciones de la Comisión pudieran darse a cabalidad, pero ello le llevaría un plazo incierto en concretarlaș.

Ante tal advertencia la Comisión presentó, el 30 de marzo de 2003, de conformidad con su propio reglamento, con el de la Corte y con la Convención Americana sobre Derechos Humanos, una demanda ante la Corte Interamericana tal como quedó plasmado en el informe establecido por el artículo 50 Convencional.

Para que el presente caso pudiese ser tratado por la Corte, la Comisión observó las dos etapas que ante la misma deben surtirse, una escrita y la otra verbal, la primera mediante la presentación de la demanda por parte de comisión la cual debe reunir una serie de requisitos, que se encuentran establecidos en el artículo 33 del reglamento de la Corte, consistentes en que la misma expresará las pretensiones $^{11}$, las partes en el caso, la exposición de los hechos, las resoluciones de apertura del procedimiento y de admisibilidad de la denuncia por la Comisión, las pruebas ofrecidas con indicación de los hechos sobre los cuales versarán, la individualización de los testigos y peritos y el objeto de sus declaraciones, los fundamentos de derecho y las conclusiones pertinentes.

Con ocasión de la participación de la Universidad Surcolombiana en el Segundo Concurso Ínteruniversitario de Derechos Humanos, en el cual correspondió a nuestra Alma Mater el desempeño del rol de Comisión, se sostuvo oralmente por parte de la misma que en el presente caso se configuraron violaciones a diferentes derechos consagrados en la Convención Americana sobre Derechos Humanos por parte del Estado.

Los Comisionados sostuvieron en defensa de los derechos de Clemencio Choachí, que el Estado era responsable internacionalmente por el desconocimiento de los derechos consagrados en la Convención Americana sobre Derechos Humanos referentes al reconocimiento de la personalidad jurídica, la vida, la integridad personal, la libertad, las

${ }^{10}$ Conforme al Artículo 50 de la Convención Americana Sobre Derechos Humanos.

11 Incluidas las referidas a las reparaciones y costas, reparaciones que no se limitan a una simple indemnización económica por el daño causado. 
garantías judiciales, los derechos del niño, la protección judicial y el desarrollo progresivo en materia de Derechos Económicos Sociales y Culturales, todos en relación con la obligación de respetar los derechos y el deber de adoptar disposiciones de derecho interno.

Por consiguiente, se debió establecer previamente con claridad, los factores que otorgaban competencia a la Corte Interamericana de Derechos Humanos para el conocimiento del presente caso $^{12}$, por lo que se fundamentó la competencia ratione materiae de la Corte, en la facultad que le asiste a ésta para conocer cualquier caso que se le someta y que concierna a la aplicación de las disposiciones de la Convención, con fundamento en el artículo 33 y $62.3 \mathrm{CADH}$.

Respecto a la competencia ratione loci, se conşideró que las violaciones aducidas, fueron cometidas en el territorio del Estado demandado, el cual como se expreso anteriormente es parte en la Convención Americana. Del mismo modo la competencia de la Corte ratione personae, se legitima por cuanto el Estado demandado había reconocido la competencia contenciosa de la Corte y en consecuencia la Comisión, acorde con al artículo 61.1 de la Convención en calidad de Ministerio Público del
Sistema Interamericano ${ }^{13}$ era quien introducía la demanda.

Por último y en consideración de la competencia ratione temporis, la cual es producto del reconocimiento internacional del principio de derecho sobre la irretroactividad de los Tratados Internacionales ${ }^{14}$, que implica que estos no deben ser aplicados a hechos ocurridos con anterioridad a la fecha de entrada en vigor para el Estado en cuestión; principio que puede variar cuando se refiere a los efectos que de carácter continuo da.la Corte a aquellas violaciones ejecutadas antes de que la misma tuviera jurisdicción respecto al Estado demandado y la violación persistió después de que el Estado prestó su consentimiento a tal jurisdicción. Al respecto, la Corte ha determinado, por ejemplo, que la denegación de justicia constituye una violación continua de la Convención ${ }^{15}$.

Con fundamento en lo expuesto, se estimó que la Corte sí poseía competencia ratio temporis respecto de los hechos conocidos, los cuales, si bien, es cierto iniciaron antes de entrada en vigor de la Convención para el Estado demandado, continuaron subsistiendo con posterioridad a que éste reconociera la competencia de la Comisión y la Corte, de tal manera que

12 OC-1\%82 Función consultiva de la Corte (artículo 64 CADH) Párr. 22.

${ }^{13}$ Corte IDH. Asunto Viviana Gallardo, Otras. Decisión de 1981, Párr. 22.

${ }^{14}$ Convención de Viena sobre el Derecho de los Tratados, 1980, Art. 28.

${ }^{15}$ Corte, Caso Genie Lacayo, Excepciones preliminares. Sentencia de 1995. Párr. 22. La Comisión reclamó que la violación de la Convención se basó principalmente en el derecho a la protección judicial, Lacayo fue asesinado por el personal militar antes de que Nicaragua hubiera aceptado la jurisdicción contenciosa de la Corte. Este organismo consideró que era competente para revisar los reclamos relativos a la denegación de justicia, estimando que esta violación era de naturaleza continua. Situaciones similares, caso Velásquez Rodríguez, Sentencia de 1988, Corte, Párr. 155 sobre desaparición forzada. 
se observaba una violación sistemática y continua a los derechos fundamentales reconocidos en la misma, lo que hace que la ésta última tenga competencia para conocer del presente caso ${ }^{16}$.

Por otra parte, la Comisión solicitó la adopción de medidas provisionales, fundamentándose en la Convención, la cual establece un sistema de protección de los derechos humanos y no un sistema resarcitorio de las violaciones a los mismos. Las medidas solicitadas tenían como fin esencial evitar hostigamientos al peticionario, pues es común que en Estados en proceso de consolidación de su democracia, quienes reclaman derechos son estigmatizados y los servicios de seguridad oficiales, generalmente, los insten al abandono de sus pretensiones bajo presiones de toda índole. Por tanto, hasta que la Corte se pronunciase definitivamente sobre el fondo del asunto, era necesario que se le brindára protección a la integridad personal del petente, sin que esto implicara la declaración de responsabilidad internacional del Estado por violación a la Convención ${ }^{17}$.

Los argumentos sostenidos por la Comisión acerca del análisis de fondo de los artículos de la Convención Americana sobre Derechos Humanos que fueron violados con la actuación del Estado demandado, en síntesis, fueron fundamentados de la siguiente forma:

Respecto a la violación a los artículos 1 y 2 de la Convención se consideró que la obligación de respetar los Derechos de la Convención con cargo a los Estados Partes, incorpora, mucho más allá de un simple mandato especifico. Los fines hacia los cuales tiende el citado documento internacional: el respeto a los derechos y libertades reconocidos por la Convención, garantizar su libre y pleno ejercicio a todas las personas, prohibir y abolir cualquier práctica de discriminación por motivos de raza, edad, sexo, idioma, religión, opiniones políticas o de cualquier índole, origen nacional o social, posición económica o de cualquier otra condición.

Estas disposiciones que gozan de poder vinculante en cuanto sustento del orden que la Convención instaura y, por ende, toda actuación u omisión que desconozca o quebrante cualquier otra norma del Tratado, lesiona el artículo $1^{\circ}$ porque traiciona sus principios.

A su vez el artículo 2 de la Convención señala que es deber de los Estados no sólo respetar los derechos civiles y políticos sino, además, garantizar, sin discriminación alguna, el libre y pleno goce de estos a toda persona sujeta a su jurisdicción, del mismo modo establece que los Estados

\footnotetext{
${ }^{16}$ Como lo ha señalado la Corte el irrespeto a las garantías judiciales; el atentado contra la integridad personal y eldesconocimiento de la personalidad jurídica, constituyen en los mismos términos violaciones sistemáticas. (Caso Genie Lacayo,

Excepciones Preliminares. Sentencia de 1995. Corte, Párr. 23-26; Caso Velásquez Rodríguez, Sentencia de 1988, Corte I.D.H. Párr. 155; Caso Blake Excepciones Preliminares, Sentencia de 1996, Corte.

${ }^{17}$ Corte, Medidas provisionales Compendio: 1987-1996. Prólogo del expresidente de la Corte, Héctor Fix-Zamudio.
} 
partes se comprometen a adoptar, con arreglo a sus procedimientos constitucionales, "las medidas legislativas o de otro carácter que fueren necesarias para hacer efectivos" los derechos humanos ${ }^{18}$. Ahora bien, la Comisión, considera que entre las medidas "de otro carácter" deben inclutrse las sentencias de los jueces y muy particularmente las decisiones de las Altas Cortes, pues la rama judicial es uno de los órganos del Estado y éste se ha comprometido a tomar las medidas que sean necesarias para hacer efectivos los derechos de las personas $^{19}$.

De los hechos que originan la presente demanda se desprende, además, que el Estado demandado no garantizó a través de sus fallos judiciales, de primera, segunda instancia y casación, proferidos contra Choachí González, ni en la tutela instaurada contra los mismos, el cumplimiénto de la citada norma internacional.

En relación con la violación al artículo 3 de la Convención, la Comisión consideró que el derecho a la personalidad jurídica no se reduce únicamente a la capacidad de la persona humana a ingresar al tráfico jurídico y ser titular de derechos y obligaciones sino que comprende, además, la posibilidad de que todo ser humano posea, por el simple hecho de existir e independientemente de su condición, determinados atributos que constituyen la esencia de su personalidad jurídica como sujeto de derecho.

La personalidad jurídica implica el reconocimiento del individuo como sujeto principal de derechos, cuyos atributos tienen valor inminente. No puede haber personas a quienes se les niegue la personalidad jurídica, ya que ello equivaldría a privarles la capacidad para ejercer derechos y contraer obligaciones.

Estos argumentos aplicados al caso, con base en el antes mencionado artículo, hacen evidente la responsabilidad del Estado al desconocer la calidad de indígena y menor de edad que posee Choachí González y que él mismo alegó durante todo el procedimiento penal y el de tutela instaurado contra el Estado, exigiendo su reconocimiento como hijo menor de una comunidad indígena. De haber prestado atención el Estado a estas reivindicaciones hechas por el procesado se le habría remitido a la Jurisdicción Especial Indígena a fin de que fuese ésta la que adelantara el procedimiento respectivo en su contra, pero no lo hizo, lo que lleva a la Comisión a denunciar tal violación a la Convención.

Refiriéndose a la violación al artículo 4.1 de la Convención la Comisión sostuvo que al interpretar tal precepto sobre el derecho a la vida, el mismo exige de los Estados Partes establecer mecanismos legales que garanticen su protección a partir de la concepción. En

${ }^{18}$ Convención Interamericana Art. $2^{\circ}$; Pacto de Derechos Civiles y Políticos Art. $2^{\circ}$ Ord. $2^{\circ}$.

${ }^{19}$ Sentencia C-109/95. 
esencia, el derecho a la vida comprende, no sólo el derecho de todo ser humano de no ser privado arbitrariamente de su existencia, sino también el derecho a que no se le impida el acceso a las condiciones que le garanticen una existencia digna. Es un principio universalmente reconocido que el derecho a la vida "no admite enfoques restrictivos" y que su garantía abarca para el Estado una obligación positiva: creàr "las condiciones que se requieran para que no se produzcan violaciones ${ }^{20}$, y el deber de impedir que sus agentes atenten contra él.

La Corte IDH ya ha dicho que garantizar la inviolabilidad de la vida implica la prevención razonable de situaciones que puedan redundar en la supresión de ese derecho ${ }^{21}$. Esta obligación del Estado se extiende, en determinadas circunstancias, al deber de tomar las medidas operativas que sean necesarias para evitar la concreción de un daño ${ }^{22}$.

En tal sentido es obligación inherente a los fines del Estado proporcionar los medios necesarios para que el individuo pueda realizar a cabalidad su proyecto de vida y éste no se vea conculcado con ocasión de la restricción de alguno de sus derechos fundamentales, pues el proyecto de vida se encuentra indisolublemente vinculado con el derecho a la libertad, implicando el derecho de cada persona a elegir su propio destino.
En razón a la vulneración del artículo 19 de la Convención, referente a los Derechos del Niño, para la Comisión fue claro que el Estado vulneró este derecho, porque al momento de ocurrencia de los hechos el petente era menor de edad, pues las disposiciones contempladas al interior de su comunidad indígena atribuyen tal calidad a quien aún no se haya iniciado sexualmente y no tenga pareja permanente. Aunque el ordenamiento jurídico del Estado, contenga otras disposiciones referentes al tema, en este caso y por respeto a los derechos humanos de Choachí es imprescindible reconocer las normas que lo cobijan en su calidad de indígena, las cuales son las únicas que conocía y que deben primar en un conflicto de normas.

Por esta razón el Estado es responsable por no respetar las disposiciones del ordenamiento interno que reconocen la autonomía de los pueblos indígenas en protección a su diversidad cultural, así como por desconocer la jurisdicción especial que plasma para los mismos en su Constitución al no otorgar valor alguno a las leyes con base en las cuales las comunidades étnicas la ejercen y en consecuencia vulneró lo dispuesto en el artículo 19 de la Convención.

En relación a la violación a los artículos 5 y 7 de la Convención, la Comisión consideró que el Estado violó el derecho a la integridad personal del

\footnotetext{
${ }^{20}$ Corte, Caso Villagrán Morales. Sentencia de 1999, Párr. 144.

${ }^{21}$ Corte, Caso Velásquez Rodríguez, $\$ 188$.

${ }^{22}$ ECHR, Osman v. the United Kingdom, Judgment Oct/98, 8116 ;
} 
peticionario, pues este fue victima de un trato tortuoso durante la etapa instructiva del procedimiento penal a causa del desabrimiento de oficiales de policía quienes lo maltrataron, a fin de lograr obtener confesión de éste.

Sobre el tema, la Corte ha expresado que el artículo 5.2 de la Convención implica, que: "toda persona privada de libertad tiene derecho a vivir en condiciones de detención compatibles con su dignidad personal y el Estado debe garantizarle el derecho a la vida y a la integridad personal. En consecuencia, el Estado, como responsable de los establecimientos de detención, es el garante de estos derechos de los detenidos» ${ }^{23}$.

El Estado, en procura del derecho a la dignidad y a las calidades especiales Choachí, debió intentar otras medidas que no afectaran tal flagrantemente sus derechos, pues la privación de la libertad durante ef tiempo de detención y reclusión, lo cual constituyó una afectación a su integridad física, psíquica y moral, desconoció el respeto debido a la dignidad que le era inherente, a su calidad de indígena, de menor de edad y, aún más, en relación a los conceptos de libertad y autonomía, propios de su descendencia indígena, constituyendo actos de torturas, tratos crueles y degradantes y violando lo artículos 5.1 y 5.2 de la Convención ${ }^{24}$.
Por consiguiente, si bien es cierto que para la época de los hechos la Convención no estaba en vigor para el Estado, sus efectos permanecieron en el tiempo, por cuanto a la fecha en que Choachí recupero la libertad ${ }^{25}$, para el Estado la Convención ya era vigente y aplicable la jurisdicción contenciosa de la Corte y de esta Comisión.

Se describió en los hechos que Choachí fue capturado el día 2 de marzo de 1995 y puesto a disposición del fiscal competente de la ciudad cinco días después de haber sido retenido, contraviniendo por parte de los agentes de policía del Estado al artículo 7.5 de la Convención ${ }^{26}$, que establece que el retenido debe ser llevado ante un juez $\mathrm{u}$ otro funcionario autorizado por la ley para ejercer funciones judiciales "dentro de un plazo razonable", por lo que la Comisión consideró que esta actuación estatal constituyó no solo un violatorio del derecho a la libertad personal, sino una evidente tortura psíquica y un trato degradante, atendiendo a la calidad del sujeto detenido y su especial cosmovisión del mundo, violando así el artículo 5 de la Convención.

Referente a la detención preventiva, como resultado de una medida de aseguramiento para garantizar la comparecencia al proceso del sindicado tal como se ha reconocido el artículo 7.5 de la Convención, la Comisión

\footnotetext{
${ }^{23}$ Caso Neira Alegría y Otros, Sentencia enero/95, Párr. 60.

${ }^{24}$ Artículos 3, 400 y 408 del C.P.P interno.

25 Corte de Casación, Sentencia Sep/01.

${ }^{26} \mathrm{El}$ artículo se recoge por el sistema interno: artículo 371 C.P.P, Ley 137 de 1994, Art. 38 y Sentencia C-024, 1994 de la Corte Constitucional: término de 36 horas para poner el capturado a disposición de autoridad judicial competente fijado en el artículo 28 Superior.
} 
considera que la misma, consistente en detención preventiva sin beneficio de excarcelación, impuesta a Choachí en el procedimiento pènal ${ }^{27}$ fue innecesaria ${ }^{28}$, como lo reafirma "el Comité de Deréchos Humanos en el sentido de que la prisión preventiva debe ser la excepción y la fianza debe ser concedida, salvo en situaciones en que haya posibilidades de que los acusados puedan esconderse o destruir pruebas, influir en los testigos o hiutr de la jurisdicción del Estado partee ${ }^{29}$.

Situación que no fue valorada por las autoridades internas del Estado y en consecuencia constituyó una violación al articulado mencionado ${ }^{30}$.

Respecto a la violación al artículo 8 y 25 de la Convención, la Comisión consideró que durante el proceso penal llevado contra indígena Choachí, se violó por el Estado los siguientes derechos y garagntías del debido proceso y la protección judicial contemplados en la Convención Americana: ser oído por un tribunal competente, independiente e imparcial (artículo 8.1); defensa (artículos 8.2.c y d), interrogar testigos (artículo 8.2.f), y protección judicial (artículo 25).

En relación con el Principio del Juez Natural, argumentó la Comisión que el mismo "impone la inderogabilidad $e$ indisponibilidad de las competencias; (...) la existencia de un Juez Natural no es dependiente exclusivamente de que haya una ley, el Juez Natural es un concepto, que desde el punto de vista del derecho internacional necesita satisfacer los réquitsitos dél artículo octavo, entre otros, de la Convención Americana" ${ }^{31 .}$

Considera la Comisión que si se hubiese tenido en cuenta, la cosmovisión de Choachí y por tanto la falta de comprensión del contenido y alcance social de la conducta desplegada por este, producto de su pertenencia e identidad con una comunidad indígena, las autoridades judiciales legítimåmente constituidas del Estado, debieron haber traslado la competencia de su juzgamiento a la comunidad de la cual era oriundo, para que fuera juzgado por tales autoridades.

Para la Comisión es claro que el artículo 8 de la Convención, garantiza sin duda alguna el derecho a una defensa técnica en el campo penal para quien sea sindicado, tanto en la etapa de investigación como en la de juzgamiento y así lo ha advertido con nitidez esta Corporación al considerar que aquella disposición, hace parte de la voluntad internacionalmente plasmada que expresamente reconoce, "los derechos y garantías judiciales fundamentales aplicables a toda clase de actuaciones judiciales que se adelantan al interior de los Estados miembros de éstan ${ }^{32}$.

\footnotetext{
${ }^{27}$ Art. 387C.P.P.

${ }^{28}$ Corte Constitucional. Sentencia, C-395 de 1994 y C-549 de 1997.

${ }^{29}$ Comité de D.H. Caso Hill. Comunicación No. 526/1993, abri/97. P. 12.3.

${ }^{30}$ Corte Constitucional, sentencia C-774, 2001.

${ }^{31}$ Caso Castillo Petruzzi otros. Argumentos de la Comisión. Párr. 125.

${ }^{32}$ Corte, Caso Genie Lacayo, sentencia sobre fondo, ene/97, Párr. 74.
} 
Así, el derecho a la defensa técnica como una modalidad específica del debido proceso penal debe aplicarse en todo caso en que exista sindicado de un delito, ya que, además, aquella es una regulación categórica y expresa de carácter normativo y de rango superior a las establecidas dentro del ordenamiento interno ${ }^{33}$.

Refiriéndose al artículo 25 Convencional, expresó que este recoge la garantía de la protección judicial a través de dos institutos: el amparo y el habeas corpus. El amparo es el procedimiento sencillo y breve que tiene por objeto la tutela de todos los derechos reconocidos por las constituciones y leyes de los Estados partes y por la Convención ${ }^{34}$, a excepción del derecho a la libertad personal, que es el que específicamente tutela el habeas corpus en el sentido en que aparece regulado por los ordenamientos americanos: Así, el habeas corpus es una espécie dentro del género del amparo en lo que hace a la tutela de la libertad personal y, como lo ha dicho esta Corte $^{35}$, surge de la lectura conjunta de los artículos 25 y 7.6 de la Convención.

Se evidencia que aunque existieron recursos internos en el Estado, Choachí se encontraba imposibilitado para utilizarlos pues nunca fue instruido sobre los mismos por parte de las autoridades. Por consiguiente, en concepto de la Corte, "no basta con que un recurso exista en la legislación interna de un país, ni que sea formalmente válido, sino también es necesario, para no violar la garantía del artículo 25, que tal recurso sea eficaz, entendiéndose por eficaz el que es capaz de producir el resultado para el cual ha sido concebido" ${ }^{36}$, por lo que se denunció por parte de la Comisión la vulneración a los artículo 8 y 25 $\mathrm{CADH}$.

Finalmente, acerca de la violación al artículo 26 de la Convención, el mismo implica en términos de la Comisión la obligación para el Estado»de garantizar a sus asociados el cumplimiento de éste a través del cabal desarrollo los derechos económicos, sociales y culturales, los cuales deben alcanzarse progresivamente, sin que esto signifique que el gobierno no tenga la obligación inmediata de empeñarse por lograr la realización plena de tales derechos. El fundamento del principio de la realización progresiva de los derechos es que los gobiernos tienen la obligación de asegurar condiciones que, de acuerdo con los recursos materiales del Estado, permitan avanzar gradual y constantemente hacia la más plena realización de tales derechos.

Así, la Comisión Interamericana de Derechos Humanos solicitó a la Honorable Corte declarar que el Estado violó los artículos $2,3,4.1,5,7,8,19$, 25 y 26 de la Convención Americana todos en relación con el artículo $1^{\circ}, 1$ ibídem; los artículos 1, 2 y 9 de la

\footnotetext{
${ }^{33}$ Corte Constitucional Colombiana, sentencias C-592/93, C-049/96.

${ }^{34}$ Artículo 25 Convención Americana sobre Derechos Humanos.

${ }^{35}$ Corte, OC-8/87, (Arts. 27.2, 25.1 y 7.6 Convención), 30 ene/87, §\$ 33-35.

${ }^{36}$ Corte, Caso Velásquez Rodríguez, Parra. 66.
} 
Convención Interamericana para prevenir y sancionar la tortura; en perjuicio del señor Clemencio Choachí González y se borrará cualquier consecuencia negativa de los procesos en su contra, requiere al Estado la modificación de su estructura gubernamental para adecuarla, conforme al artículo 2, a las" disposiciones de la Convención y adoptar las medidas necesarias para una justa reparación a la víctima del presente caso.

En este orden de ideas, se fundamentó la defensa de los derechos humanos Clemencio Choachí González ante la Corte Interamericana contra el Estado, representada por los suscritos estudiantes de Facultad de Derecho en calidad de comisionados ante este Tribunal internacional, el cual tomando habida consideración de los alegatos de ambas partes, estará presta a dictar sentencia conforme encuentre pertinente.

Este fue, entonces, el tema y objeto del Concurso Ínteruniversitario de Derechos Humanos, el cual persigue principalmente la divulgación, conocimiento y manejo de los derechos humanos y de su eficacia en el sistema Interamericano, no queda más que invitar al lector que logró llegar al final de este texto a participar en este concurso y tener el gusto de conocer una de las más engrandecedoras y gratificantes experiencias universitarias. $\infty^{\circ}$ 